\title{
APOIO: A FORMA PREDOMINANTE DE PARTICIPAÇÃO MASCULINA NA REGULAÇÃO DA FECUNDIDADE DO CASAL*
}

\author{
Marta Lúcia O.Carvalho** \\ Katia Cibelle MachadoPirotta*** \\ Neia Schor ${ }^{\star \star \star *}$
}

\begin{abstract}
RESUMO: 254 mulheres em idade reprodutiva, usuárias de métodos contraceptivos reversíveis, que referiam ter parceiro sexual, foram entrevistadas em seus domicílios, na região sul de São Paulo, com o objetivo de identificar como elas definem as formas de participação masculina na contracepção, a partir da percepção sobre atitudes de seus parceiros, $82,7 \%$ das entrevistadas referiram que seus parceiros participavam do processo de regulação da fecundidade, apesar de $78,8 \%$ delas usarem métodos femininos, o que aponta para a desvinculação entre o tipo de método contraceptivo usado e a percepção dessas mulheres a respeito da participação masculina na regulação da fecundidade do casal. Observou-se neste estudo que a forma predominante de participação masculina na contracepção esteve associada à função de apoio ao uso de método feminino de alta eficácia. Observou-se, nas respostas das mulheres, que estas assumem a contracepção como uma tarefa de sua responsabilidade, e o papel do homem como acessório, de apoio à essa função.
\end{abstract}

PALAVRAS-CHAVE: contracepção, métodos contraceptivos, regulação da fecundidade, participação masculina, apoio

\footnotetext{
* Trabalho realizado no Departamento de Saúde Materno-Infantil - Faculdade de Saúde Pública da Universidade de São Paulo. Projeto financiado com auxílio CNPq (processo no 91/0036-4) e da FAPESP (processo no 502722/91-6)

** Enfermeira, Professora Adjunta do Departamento de Enfermagem da Universidade Estadual de Londrina - Paraná, Mestre em Enfermagem, Doutoranda do Departamento Materno-Infantil da Faculdade de Saúde Pública da Universidade de São Paulo

*** Socióloga, Mestre em Saúde Pública, Doutoranda do Departamento de Saúde Materno-Infantil da Faculdade de Saúde Pública da Universidade de São Paulo

**** Professora Associada do Departamento de Saúde Materno-Infantil da Faculdade de Saúde Pública da Universidade de São Paulo
} 


\section{INTRODUÇÃO}

Na América Latina e Caribe, em $80 \%$ dos casos, toda a responsabilidade e riscos das práticas contraceptivas são assumidos pelas mulheres (RIOS, 1993), ilustrado pela predominância de métodos contraceptivos de uso feminino, que prescindem da participação masculina, como a pílula anticoncepcional e a esterilização feminina.

No Brasil a situação é similar, como podemos observar na TABELA 1, onde reuniuse os métodos contraceptivos usados no país em dois grupos:

Tabela 1 - Distribuição de todas as mulheres em idade reprodutiva e das mulheres unidas em idade reprodutiva, segundo tipo de método contraceptivo que usam. Brasil - 1996

\begin{tabular}{l|cc}
\hline Tipos de Métodos Contraceptivos em uso & todas as mulheres & mulheres unidas \\
\hline independentes de participação masculina $\left(^{*}\right)$ & $81,92 \%$ & $82,79 \%$ \\
dependentes de participação masculina $\left(^{* \star}\right)$ & $18,08 \%$ & $17,21 \%$ \\
\hline TOTAL & $100,00 \%$ & $100,00 \%$ \\
\hline
\end{tabular}

(*) inclui esterilização feminina, pílula, injetáveis, DIU, outros (ervas, chás, etc)

$\left({ }^{\star *}\right)$ inclui esterilização masculina, condom, coito interrompido e os métodos de abstinência periódica (tabela, muco cervical e temperatura basal)

Fonte: dados extraídos da Pesquisa Nacional sobre Demografia e Saúde / BENFAM 1996.

A definição do termo "participação masculina na contracepção" pode significar desde o uso de métodos masculinos (condom, coito interrompido e vasectomia), até a cooperação nos métodos de abstinência periódica, ou ainda, como afirma OMONDI-ODHIAMBO (1997, p.36), significa mais freqüentemente "estar de acordo com suas companheiras, permitindo que elas usem contraceptivos".

A preocupação com o pouco envolvimento masculino nas atividades de contracepção está vinculada a outras questões relevantes na área de Saúde Reprodutiva, como o aumento da incidência de mulheres infectadas pelo HIV ou outras doenças sexualmente transmitidas, o que poderia ser minimizado com o uso do condom, e ainda o aumento do número de gestações não planejadas, com repercussões na qualidade de vida das mulheres. 
A Constituição Federal Brasileira de 1988 prevê o direito de informação e acesso dos casais aos meios de regulação da fertilidade. É desnecessário reafirmar a importância do controle das mulheres sobre sua fecundidade que, ao lado de outras ações como o acesso à educação e à formação profissional, constituem-se em condições necessárias, ainda que não suficientes, para a efetiva melhoria da qualidade de vida da população feminina.

Entre os fatores que poderiam estar reforçando a falta de participação masculina na contracepção, apontam-se a ausência de informação e de incentivo ao uso dos métodos masculinos e a divisão, socialmente construída, de papéis entre os sexos, que atribui apenas à mulher a tarefa de regular o tamanho da prole.

A ênfase da maioria das iniciativas em programas de planejamento familiar ou saúde reprodutiva também enfocam a mulher. Praticamente inexistem serviços de planejamento familiar dirigidos à clientela masculina nos serviços públicos, com horários adequados, desvinculados dos serviços de ginecologia, e que além de informação adequada sobre contracepção, provisão de condons e oferta de vasectomia, trate de questões como sexualidade e prevenção de doenças sexualmente transmitidas e HIV / AIDS, de preferência com profissionais de saúde do sexo masculino (POPULATION REFERENCE BUREAU,1995; RINGHEIN, 1993).

Alguns dos motivos pelos quais muitos homens realmente resistem à participação em atividades de contracepção, ou até mesmo a que suas companheiras usem contraceptivos seriam: por associarem a virilidade à fertilidade; por considerarem que o uso da contracepção por suas mulheres poderia predispor à infidelidade; por motivos religiosos; por medo de enfraquecimento de sua autoridade de chefe de família e por medo de possíveis efeitos colaterais dos métodos contraceptivos (GALLEN E COLS. 1987; RINGHEIN, 1993). Além disto, o condom interferiria no prazer; o coito interrompido prejudicaria a espontaneidade do ato sexual e a vasectomia por ser irreversível ou por ser erroneamente associada à castração. Em pesquisa participativa realizada no Rio de Janeiro, $72 \%$ dos homens permitiria que sua mulher fizesse laqueadura, mas igual porcentagem não faria a vasectomia (GIFFIN,1994).

As opções de métodos contraceptivos masculinos reversíveis ou temporários são realmente muito limitadas se comparadas às opções para uso da mulher. Apenas dois métodos, condom e coito interrompido, compõem o leque de escolhas. Inexiste um método masculino de alta eficácia comparável aos métodos hormonais femininos ou ao DIU, o que, num país sem o recurso ao aborto legal em caso de falha do método, pode ser um importante fator pesando na decisão dos indivíduos (PERPÉTUO \& WAJMAN, 1992; RINGHEIN, 1993).

CORREA \& PETCHESKY (1996), defendendo os direitos reprodutivos das mulheres, 
denuncia a falta de atenção a estes direitos, levantando polêmica inclusive sobre a redação da "Convenção para Eliminação de Todas as Formas de Discriminação contra as Mulheres", das Nações Unidas, onde encontra-se a afirmação que homens e mulheres teriam os mesmos direitos para decidirem sobre o número de filhos que desejariam ter. Esta visão sobre os direitos reprodutivos dos indivíduos traria em si uma contradição, uma vez que só as mulheres engravidam e, portanto, não podendo sua situação ser igualada à dos homens.

Reforçando uma hipótese de desconfiança das mulheres em relação à participação masculina na contracepção, estudo realizado em 1973 nos EUA perguntou a elas sobre uma hipotética pílula anticoncepcional masculina: $72 \%$ das entrevistadas respondeu que mesmo com a real possibilidade de vir a existir este método, ainda prefeririam manter 0 controle sobre sua própria fecundidade, indicando que as maiores conseqüências de uso incorreto ou falha do método recairiam sobre elas (RINGHEIN, 1993).

O controle da mulher sobre sua própria fecundidade é considerado um dos pilares do processo de "empowerment" da mulher (traduzido como "empoderamento"). Recaindo sobre a mulher as conseqüências de uma gravidez não planejada ou até mesmo indesejada, é natural que a mulher queira assumir ela mesma a tarefa da contracepção.

Trazendo a questão da responsabilidade sobre a contracepção como devendo ser compartilhada entre os sexos, a Conferência de Beijing destaca também a necessidade da mulher controlar sua própria fecundidade. Se dividida a responsabilidade com o homem, ainda seria uma expressão de autonomia da mulher, de poder sobre seu próprio corpo? Ou esta participação do companheiro seria requerida mais no sentido de apoio, reforçando um estilo de união mais solidário? Ou ainda, reconhecendo a posição submissa de grande contingente de mulheres, ao invés de trabalhar no sentido do "empowerment" dessas mulheres, tentar sensibilizar o lado mais forte do casal sobre a necessidade de controle do aumento da prole? Muitas são as indagações neste campo da contracepção que envolve argumentos e motivações várias, desde várias vertentes de luta pela emancipação feminina até interesses de várias origens sobre o controle populacional.

\section{OBJETIVOS}

- Identificar as percepções de um grupo de mulheres, usuárias de métodos contraceptivos reversíveis, sobre o que tem sido a participação de seus companheiros nas atividades de contracepção, e como elas expressam esta participação. 
- Caracterizar este grupo de mulheres segundo idade, escolaridade, situação conjugal, participação no mercado de trabalho e contribuição no orçamento doméstico, método anticoncepcional usado e participação do parceiro no processo de regulação da fecundidade do casal.

\section{MATERIAL E MÉTODO}

O estudo, cujos resultados são discutidos neste artigo, foi um desdobramento do projeto maior intitulado "Mortalidade e Morbidade Maternas, Qualidade de Assistência e Estrutura Social: Estudo da Região Sul do Município de São Paulo" (SIQUEIRA,1993 et al.; SCHOR, 1995; PIROTTA, 1998).

A região pesquisada abarcou os subdistritos de Santo Amaro e Capela do Socorro e o distrito de Parelheiros, com população de 1.662.231 habitantes, segundo contagem do Censo em 1991 (FUNDAÇÃO IBGE, 1991). O presente estudo versou sobre as mulheres que referiram estar usando métodos anticoncepcionais reversíveis no momento da entrevista, cujo grupo somou 254 mulheres. Estas foram caracterizadas segundo variáveis sociodemográficas ( idade, escolaridade, situação conjugal, participação no mercado de trabalho e contribuição no orçamento doméstico) e segundo método contraceptivo usado no momento da entrevista, com análise estatística destes resultados. As respostas às questões abertas sobre participação do parceiro na regulação da fecundidade (modo de participação ou motivo pelo qual não participa) foram analisadas segundo método de Análise de Conteúdo (BARDIN, 1995).

\section{RESULTADOS E DISCUSSÃO}

Entre as mulheres pesquisadas, $82,7 \%$ afirmaram que o parceiro participava da contracepção, apesar dos principais métodos utilizados neste grupo serem a pílula e esterilização feminina. (TABELA 2)

A idade média observada foi igual a 28,4 anos, a idade mediana a 27,0 anos e o desvio padrão a 7,7 anos. $59,8 \%$ das mulheres pesquisadas apresentaram idade inferior a 30 anos, caracterizando o grupo das usuárias de métodos reversíveis como um grupo jovem. (TABELA 2)

Em estudo sobre a trajetória reprodutiva da mulher realizado nesta mesma região (PIROTTA, 1998; PIROTTA \& SCHOR, 1998) constatou-se que as mulheres iniciaram sua 
vida sexual, em mediana, aos 19 anos e, por não usarem métodos anticoncepcionais nas primeiras relações sexuais, engravidaram precocemente, tendo o primeiro filho aos 20 anos. A partir daí, elas passaram a usar métodos contraceptivos, sobretudo a pílula, e no prazo de 10 anos estavam se esterilizando.

Observou-se, neste grupo,escolaridade mais alta do que as demais mulheres residentes nesta região, mas um dos elementos que devem ser considerados na análise é o fato de que o grupo de usuárias de métodos temporários era mais jovem e talvez com mais oportunidade de acesso à escolarização.

Ao observar-se a distribuição da variável escolaridade nos dois grupos, constatouse que a proporção das mulheres que afirmaram que o parceiro participa da contracepção foi alta em todos os intervalos, tendendo a elevar-se conforme o nível de escolaridade aumentava, e constatando-se a presença marcante das universitárias no grupo das que mencionaram a participação do parceiro $(96, \%)$. O grupo das analfabetas, por sua vez, foi o que menos referiu a participação masculina $(66,7 \%)$.(TABELA 2$)$

Em relação ao método anticoncepcional usado no momento da entrevista, a maioria das mulheres $(67,3 \%)$ referiu a pílula(TABELA 2$)$, método referido em diversas pesquisas como o principal método usado pelas mulheres brasileiras sendo superada somente pela esterilização feminina. (PERPÉTUO \& AGUIRRE, 1998; BEMFAM, 1997; PATARRA, 1995; BERQUÓ, 1993; MORELL, 1992). 
TABELA 2 - Distribuição em número e porcentagem das usuárias de métodos contraceptivos temporários segundo características gerais e participação masculina no processo de regulação da fecundidade do casal - Região Sul do Município de São Paulo, 1992.

\begin{tabular}{|c|c|c|c|c|c|c|}
\hline \multirow{2}{*}{$\begin{array}{l}\text { Características } \\
\text { Idade (anos) }\end{array}$} & \multicolumn{4}{|c|}{$\begin{array}{ll}\text { Participação masculina na contracepção } \\
\text { parceiro } & \text { parceiro } \\
\text { participa } & \text { não participa }\end{array}$} & \multicolumn{2}{|c|}{ Total } \\
\hline & No\% & & $\mathrm{N}^{\circ}$ & $\%$ & No & $\%$ \\
\hline 15 a 19 & 22 & 84.6 & 04 & 15.4 & 26 & 100.0 \\
\hline 20 a 24 & 56 & 87.5 & 08 & 12.5 & 64 & 100.0 \\
\hline 25 a 29 & 51 & 82.2 & 11 & 17.8 & 62 & 100.0 \\
\hline 30 a 34 & 37 & 77.1 & 11 & 22.9 & 48 & 100.0 \\
\hline 35 a 39 & 24 & 82.7 & 05 & 17.3 & 29 & 100.0 \\
\hline $40 \mathrm{e}+$ & 20 & 80.0 & 05 & 200 & 25 & 100.0 \\
\hline
\end{tabular}

Escolaridade (anos completos)

$\begin{array}{lllllll}\text { analfabeta } & 04 & 66.7 & 02 & 33.5 & 06 & 100.0 \\ 1 \text { a } 4 & 66 & 78.6 & 18 & 21.4 & 84 & 100.0 \\ 5 \text { a } 8 & 75 & 83.3 & 15 & 16.7 & 90 & 100.0 \\ 9 \text { a } 11 & 41 & 83.7 & 08 & 16.3 & 49 & 100.0 \\ 12 \text { e }+ & 24 & 96.0 & 01 & 4.0 & 25 & 100.0\end{array}$

Situação conjugal

$\begin{array}{lllllll}\text { solteira } & 38 & 82.6 & 08 & 17.4 & 46 & 100.0 \\ \text { unida } & 169 & 82.8 & 35 & 17.2 & 204 & 100.0 \\ \text { não-unida } & 03 & 75.0 & 01 & 25.0 & 04 & 100.0\end{array}$

Participação no mercado de trabalho e contribuição no orçamento doméstico

$\begin{array}{lllllll}\text { sim, responsável } & 24 & 80.0 & 06 & 20.0 & 30 & 100.0 \\ \text { sim, co-responsável } & 90 & 83.3 & 18 & 16.7 & 108 & 100.0 \\ \text { sim, mas não contribui } & 18 & 78.3 & 05 & 21.7 & 23 & 100.0 \\ \text { não, dependente } & 78 & 83.9 & 15 & 16.1 & 93 & 100.0\end{array}$

Método contraceptivo

$\begin{array}{lllllll}\text { Condom } & 25 & 96.2 & 01 & 3.8 & 26 & 100.0 \\ \text { Coito interrompido } & 16 & 94.1 & 01 & 5.9 & 17 & 100.0 \\ \text { Abstinência periódica } & 09 & 81.8 & 02 & 18.2 & 11 & 100.0 \\ \text { Pílula } & 136 & 79.5 & 35 & 20.5 & 171 & 100.0 \\ \text { DIU } & 06 & 75.0 & 02 & 25.0 & 08 & 100.0 \\ \text { Injetável } & 05 & 71.4 & 02 & 28.6 & 07 & 100.0 \\ \text { Diafragma } & 03 & 100.0 & - & & 03 & 100.0 \\ \text { Outros } & 10 & 90.9 & 01 & 9.1 & 11 & 100.0\end{array}$

$\begin{array}{llllll}\text { TOTAL } & 210 & 82.744 & 17.3 & 254 & 100.0\end{array}$ 
Segundo MARCOLINO \& SCHOR (1995, p.87), “A pílula é o método mais conhecido e usado. Ocorre, no entanto, o abandono do seu uso, associado a três principais motivos: problemas de saúde que contra-indicam sua continuidade, efeitos colaterais e falhas." Segundo as autoras, a mulher também encontra dificuldade com outros métodos como, por exemplo, a abstinência periódica, que depende de um conhecimento preciso do corpo e dos ritmos ligados à fertilidade, e o condom, que depende do parceiro.

Não foi encontrada associação significativa entre a percepção da participação masculina e as variáveis: idade, situação conjugal ou participação no orçamento doméstico. Detectou-se uma esperada associação significativa, mas fraca, entre uso de MAC masculino e a percepção de participação masculina $\left(c^{2}=5,05, p=0,024\right)$. Foi constatada também uma tendência das mulheres com maior escolaridade referirem a participação masculina.

Com base nas respostas às questões abertas sobre a participação masculina, dois quadros de categorias foram construídos para permitir a organização desses corpus de dados em uma série de caracterizações dadas pelas entrevistadas:

· às formas de "participação masculina" (QUADRO 1) e

- aos motivos pelos quais elas entendiam que o companheiro não participava (QUADRO 2). 


\section{Quadro 1 - FORMAS DE PARTICIPAÇÃO MASCULINA NA CONTRACEPÇÃO DE ACOR- DO COM RESPOSTAS DAS MULHERES ENTREVISTADAS}

\begin{tabular}{|c|c|c|c|}
\hline CATEGORIA & DESCRIÇÃO & No & $\%$ \\
\hline 1. Apenas apoio & $\begin{array}{l}\text { - sem referência ao } \\
\text { uso de método mascu- } \\
\text { lino, homem participa } \\
\text { "opinando sobre núme- } \\
\text { ro de filhos"; "cuidando } \\
\text { que a mulher não es- } \\
\text { queça de tomar"; "com- } \\
\text { prando pílula ou } \\
\text { injetável"; "aceitando } \\
\text { que a mulher use mé- } \\
\text { todo feminino". }\end{array}$ & 78 & $36,97 \%$ \\
\hline $\begin{array}{l}\text { 2. uso eventual de } \\
\text { método masculino }\end{array}$ & $\begin{array}{l}\text { - homem usa método } \\
\text { masculino apenas } \\
\text { quando a mulher inter- } \\
\text { rompe o uso de méto- } \\
\text { do feminino. }\end{array}$ & 76 & $36,02 \%$ \\
\hline $\begin{array}{l}\text { 3. uso rotineiro de } \\
\text { método masculino }\end{array}$ & $\begin{array}{l}\text { - homem usa método } \\
\text { masculino ininter- } \\
\text { ruptamente. }\end{array}$ & 40 & $18,96 \%$ \\
\hline \multirow[t]{2}{*}{$\begin{array}{l}\text { 4. participação em } \\
\text { método de abstinên- } \\
\text { cia periódica }\end{array}$} & $\begin{array}{l}\text { - casal usando método } \\
\text { de abstinência periódi- } \\
\text { ca, que necessita par- } \\
\text { ticipação masculina. }\end{array}$ & 17 & $8,05 \%$ \\
\hline & TOTAL & 211 & $100,00 \%$ \\
\hline
\end{tabular}

Na categoria 1 - "Apenas apoio" em todas as respostas o homem aparece como quem dá suporte ou apoia uma atividade que é da mulher, sendo esta o sujeito ativo das ações contraceptivas, principalmente através do uso da pílula.

- "ele compra a pílula para mim, pergunta se estou tomando direitinho"

- "se eu esqueço de tomar a pílula, ele me lembra"

. "ele paga as injeções" 
Nas respostas incluídas na categoria 2 - "Uso eventual de método masculino", notase que a atribuição do uso do contraceptivo continua sendo da mulher - o homem apenas ajuda, apoia, em caso de impossibilidade da mulher exercer o papel principal na contracepção.

- "teve uma época que eu não podia tomar a pílula, aí ele evitava"

. "quando estou sem o remédio, ele usa a camisinha"

. "quando eu faço o descanso da pílula, ele usa a camisinha"

Na categoria 3 - "Uso rotineiro de método masculino", onde não houve citação do uso de método feminino ou consensual, existiam muitas referências à comunicação entre os parceiros na decisão sobre o número de filhos. Mas mesmo aqui, observou-se também, em algumas respostas, uma posição pouco ativa do homem em relação à contracepção, com o homem "concordando" com o pedido da mulher que se justifica por não poder tomar a pílula devido a algum problema de saúde.

- "ele concorda em usar a camisinha

- "a gente está usando camisinha"

. "nem ele nem eu queremos filhos, então ele tira fora"

Na categoria 4 - "Participação em métodos de abstinência periódica" encontrou-se a maior concentração de respostas que explicitam conversas entre o casal, como era de se esperar num método de uso consensual.

- "a gente faz tabelinha ou coito interrompido, já atingimos a nossa meta que é um casal"

. "às vezes ele compreende que existem dias que não podemos ter relações"

- "conversando, pensando junto. Ele gostaria de ter mais filhos, mas não impõe, pois acha que a decisão é da mulher. Ele não impõe o que ele quer"

Nas respostas à questão "Por que seu companheiro não participa" (QUADRO 2), as mulheres entrevistadas interpretam os motivos da ausência masculina.

Na categoria 1 - "Ter que fazer tudo sozinha", de maior incidência neste quadro $(54,55 \%)$, encontrou-se queixas a respeito da não participação masculina:

. "a gente nunca conversou sobre isso - eu é que faço tudo, se quiser" 
- "ele não faz nada prá me ajudar"

- “ele não tá nem aí. Ele acha que prá ele não tem responsabilidade.; ele acha que eu é que tenho que ser prevenida"

. "porque ele não quer pôr nada nele - quem tem que evitar sou eu"

- "se ele me ajudasse eu me liberava da pílula"

\section{QUADRO 2 - MOTIVOS PELOS QUAIS O COMPANHEIRO NÃO PARTICIPA DA CONTRACEPÇÃO, SEGUNDO VISÃO DAS MULHERES ENTREVISTADAS}

\begin{tabular}{|c|c|c|c|}
\hline CATEGORIA & DESCRIÇÃO & No & $\%$ \\
\hline $\begin{array}{l}\text { 1. ter que fazer tudo so- } \\
\text { zinha }\end{array}$ & $\begin{array}{l}\text { - mulher se queixando da } \\
\text { não participação do homem } \\
\text { na contracepção }\end{array}$ & 24 & $54,44 \%$ \\
\hline $\begin{array}{l}\text { 2. não é necessário, não } \\
\text { precisa. }\end{array}$ & $\begin{array}{l}\text { - mulher dispensando / pou- } \\
\text { pando o homem e assumin- } \\
\text { do o controle da reprodução }\end{array}$ & 12 & $27,27 \%$ \\
\hline \multirow[t]{2}{*}{ 3. ele quer mais filhos } & $\begin{array}{l}\text { - decisão sobre tamanho da } \\
\text { prole não é consensual }\end{array}$ & 08 & $18,18 \%$ \\
\hline & TOTAL & 44 & $100,00 \%$ \\
\hline
\end{tabular}

Se a ocorrência de 20 usuárias de pílula, entre as 24 entrevistadas desta categoria poderia indicar que a pílula vem sendo a alternativa possível para estas mulheres cujos companheiros não dividem a responsabilidade do controle da fecundidade, chama a atenção a ocorrência de dois casos onde o método usado é masculino (coito interrompido e condom). Tendo, nestes casos, o homem assumido concretamente o controle da reprodução, de que falta de participação masculina estas mulheres falam ? Em alguns destes casos, há referências explícitas a problemas de comunicação entre o casal ( "a gente nunca conversa sobre isso"; "não converso disso com ele"; "converso e ele não diz nada"). Estarão estas mulheres expressando a falta de participação masculina como a falta de diálogo no planejamento da prole ? A falta de comunicação entre o casal é também um dos fatores considerados como importantes no pouco envolvimento masculino na contracepção. 
Em 27,27\% dos casos em que o companheiro não participava, não havia uma queixa explícita, mas uma idéia de dispensa do homem dessa atividade (categoria 2 - "Não é necessário, não precisa"). Neste grupo de respostas pode-se inferir mulheres assumindo, por opção pessoal ou por papel socialmente atribuído, a regulação de sua fecundidade, reforçando ainda mais uma representação da contracepção como uma atividade feminina.

. "eu mesma já vou preparada, não tem necessidade"

- "ele não pode me ajudar porque já tem os problemas dele"

. "eu tomo a pílula, então ele não precisa me ajudar"

A alta incidência de usuárias de pílula nesta categoria pode sugerir que a escolha deste método, por sua alta eficácia, e que prescinde da participação masculina, possa estar participando na criação deste padrão de resposta.

É interessante assinalar que entre os casos da categoria 3 - "Ele quer mais filhos", apenas uma mulher não era usuária de método contraceptivo feminino de alta eficácia (hormonais ou DIU). Não havendo consenso sobre o tamanho da prole, através do uso desses métodos femininos, a mulher poderia manter o controle sobre a sua própria fecundidade, como um exercício de autonomia.

\section{CONCLUSÃO}

$\mathrm{Na}$ visão das maioria das mulheres entrevistadas $(82,7 \%)$, seus maridos ou companheiros participam da contracepção. O que elas interpretam como participação masculina está majoritariamente vinculado a uma concepção de apoio ao uso de métodos femininos de alta eficácia. A maior parte dos homens que usam condom ou outros métodos masculinos, apenas o fazem quando a mulher interrompe temporariamente o uso da pílula (ou injetável). Mesmo nas respostas das mulheres que afirmaram que o companheiro "não participava", grande porcentagem os exime da responsabilidade ("não precisa, eu já tomo a pílula"; "não tem necessidade, eu já vou prevenida"). Em todos esses casos, encontramos a mulher assumindo a contracepção como atividade de sua responsabilidade e o papel do homem como acessório, auxiliar, de apoio.

Não foi encontrada associação significativa entre a percepção da participação masculina e variáveis como idade, situação conjugal ou participação no orçamento doméstico. Detectou-se uma esperada associação significativa, mas fraca, entre uso de MAC masculino e a percepção de participação masculina. Foi constatada também uma tendência das mulheres com maior escolaridade referirem a participação masculina. 
As relações entre homens e mulheres refletem os padrões culturais de uma sociedade. A mulher vem conquistando um espaço cada vez maior no mundo público, entrando no mercado de trabalho e assumindo a co-responsabilidade ou até a responsabilidade no sustento da família, ainda que muitas vezes isto não aconteça por uma opção deliberada e sim por determinações econômicas. Mas seja qual for a motivação, não é tão comum a necessária divisão com o homem das tarefas do mundo privado. O cuidado dos filhos e o controle da fecundidade ainda são considerados, pela sociedade e até pelas próprias mulheres, como uma função feminina. As atividades de contracepção são majoritariamente assumidas pela mulher, cabendo ao homem uma função acessória, de apoio a esta atividade.

Pode-se inferir um exercício de poder da mulher sobre seu próprio corpo, regulando a sua fecundidade e seu destino biológico da procriação, considerando que as conseqüências de uma gravidez indesejada recairiam sobre ela? E neste caso, talvez em uma armadilha de gênero, a mulher assumindo sozinha a contracepção estaria liberando mais uma vez 0 homem das tarefas do mundo privado, da família.

Poderia haver também um desvio de gênero na pesquisa de métodos contraceptivos que, tendo desenvolvido métodos reversíveis de alta eficácia apenas para as mulheres, possa ter contribuído para a alta incidência da pílula e da esterilização, encontrado nos estudos sobre a contracepção. Como afirma VILLELA \& BARBOSA (1996, p.458), "eficácia e praticidade passam a ser os atributos mais importantes para a mulher no momento da escolha contraceptiva, fazendo com que os potenciais efeitos colaterais ou agravos à saúde não sejam valorizados". Num momento econômico em que a preocupação maior parece residir no custo da criação dos filhos, conforme encontramos em muitas respostas, a eficácia da contracepção pode ser o fator realmente determinante da escolha do método, principalmente num país onde não existe o recurso ao aborto legal em caso de falha do método contraceptivo, conforme ressalta BERQUÓ (1993).

Muitas hipóteses são possíveis. Provavelmente todas sejam reais, uma vez que a somatória de determinantes sociais e predisposições pessoais produzem sempre mulheres e homens diferentes entre si. No direito à diferença e à opção informada, com acesso às várias opções contraceptivas, cabe aos serviços de saúde prover as condições mínimas para o exercício dos direitos reprodutivos de mulheres e homens - a informação e o acessos aos métodos. Aos órgãos de pesquisa, caberia fomentar o desenvolvimento de métodos contraceptivos reversíveis de alta eficácia para uso masculino. Os pesquisadores, deveriam coletar mais dados qualitativos que possam esclarecer motivações, dúvidas e expectativas de homens e mulheres em relação à contracepção, com a finalidade de direcionar a pesquisa de novas tecnologias de encontro às necessidades dos usuários. 


\section{AGRADECIMENTOS}

Agradecemos ao CNPq e à FAPESP.

\section{REFERÊNCIAS BIBLIOGRÁFICAS}

BARDIN, L. Análise de Conteúdo. Lisboa, Edições 70, 1995.

BENFAM. Brasil - Pesquisa Nacional sobre Demografia e Saúde - 1996. Rio de Janeiro, 1997.

BERQUÓ, E. Brasil um caso exemplar: anticoncepção e partos cirúrgicos. Campinas, Núcleo de Estatística Populacional da UNICAMP, 1993. [Apresentado ao Seminário "A situação da mulher e o desenvolvimento", Campinas, 1993]

CORREAA, S.; PETCHESKY, R. Direitos Sexuais e Reprodutivos: uma perspectiva feminista. PHYSIS: Rev. Saúde Coletiva, 6.147-177, 1996.

DRENNAN, M. "Reproductive health: new perspectives on men's participation." In: Population Reports, Series J, $n^{\circ} 46$. Baltimore, Johns Hopkins University School of Public Health, Population Information Program, October, 1998.

FUNDAÇÃO IBGE. Sinopse preliminar do censo demográfico. São Paulo, 1991.

GIFFIN, K. Esfera de Reprodução em uma visão masculina: considerações sobre a articulação da produção e da reprodução de classe e gênero. PHISYS - Rev. Saúde Coletiva, 4:23-40, 1994.

MARCOLINO, C \& SCHOR, N. Trajetória da mulher em direção à esterilização cirúrgica feminina: um estudo fenomenológico. Rev. Bras. Cresc. Desenv. Hum., 5:82-95, 1995.

MORELL, M.G.G.P.de A prática de esterilizações em São Paulo: uma tentativa de caracterização. In: VIII Encontro Nacional de Estudos Populacionais, Caxambú, 1992. ANAIS. São Paulo, Associação Brasileira de Estudos Populacionais, 1992. v.2 p.61-82

OMONDI-ODHIAMBO Men's participation in Family Planning decisions in Kenya. Population Studies, 51:29-40, 1997. 
PATARRA, N.L. Mudanças na dinâmica demográfica. In: Monteiro, C.A. (org.) Velhos e novos males da saúde no Brasil - a evolução do país e suas doenças. São Paulo, HUCITEC, 1995.

PERPÉTUO, I.H.O. \& AGUIRRE, M.A.C. "O papel da esterilização feminina nos diferenciais sócioeconômicos do declínio da fecundidade no Brasil" In: Encontro Nacional de Estudos Populacionais, $11^{\circ}$,Caxambú, 1998. ANAIS: Belo Horizonte, ABEP, 1998. Publicação em meio eletrônico (CD-ROM). p.2997-3024.

PERPÉTUO, I.H.O.; WAJMAN, S. A mulher que se esteriliza no Brasil. In: Encontro Nacional de Estudos Populacionais, $8^{\circ}$, São Paulo, 1992. ANAIS: São Paulo, ABEP, 1992. p 2341.

PIROTTA, K.C.M. \& SCHOR, N. "A mulher e a esterilização: a trajetória rumo à laqueadura tubária" In: Encontro Nacional de Estudos Populacionais. 11 Caxambú, 1998. ANAIS: Belo Horizonte, ABEP, 1998. Publicação em meio eletrônico (CD-ROM). p.121-49.

PIROTTA, K.C.M. A mulher e a esterilização: do mito da emancipação ao desvelamento da subalternidade. São Paulo, 1998. [Dissertação de mestrado - Faculdade de Saúde Pública da USP]

POPULATION REFERENCE BUREAU Inquietudes Femininas: las mujeres escribem sobre la participación de los hombres en la familia. Washington,DC, julio, 1995.

RINGHEIN, K. Factors that determine prevalence of use of contraceptive methods for men. Studies in Family Planning, 24:87-99, 1993.

RIOS, R. Genero, Salud y Desarrollo: un enfoque en construccion. In: Gomez, E.G. (ed.) Genero, Mujer y Salud en las Americas. Washington, DC1993. (OPS/OMS, Publicacion Cientifica $n^{\circ} 541$ )

SCHOR, N. Adolescência e anticoncepção: conhecimento e uso. São Paulo, 1995. [Tese de Livre-docência - Faculdade de Saúde Pública da USP]

SIQUEIRA, A.A.F.de et al. Estudo da mortalidade materna na Região Sul do Município de Estado de São Paulo, Brasil: análise preliminar. São Paulo, Faculdade de Saúde Pública da USP, 1991. (Série de Investigação em Saúde da Mulher, da Criança e Adolescencia,1).

SIQUEIRA, A.A.F.de et al. Morbidade e mortalidade maternas, qualidade da assistência e estrutura social: estudo da Região Sul do Município de São Paulo - Brasil. Parte II. Morbidade materna. São Paulo, 1993 [Relatório Final, apresentado à FAPESP] 
VILELLA, W.; BARBOSA; R. Opções Contraceptivas e Vivências da Sexualidade: comparação entre mulheres esterilizadas e não esterilizadas em região metropolitana de sudoeste do Brasil. Rev. Saúde Pública, 30:452-9, 1996.

\section{SUPPORT: THE PREDOMINATING FORM OF MALE PARTICIPATION IN REGULATING THE COUPLE FERTILITY}

SUMMARY:Two hundred and fifty four women of childbearing age, using reversible contraceptive methods and reporting to have sexual partners were interviewed in their houses, in the Southern region of São Paulo. The objective was to identifity how they define male participation in contraception, based on the perception of attitudes of their partners. Out of the 254 subjects, $82,7 \%$ mentioned their partners participated in the fertility regulation process, although $78,8 \%$ of them used female methods. This points out to a separation between the kind of contraceptive method used and the perception of these women of the male participation in regulating the couple fertility. It was observed that the predominating form of male participation in contraception was associated to support the high-efficacy female method used. It was also verified that women, according to their answers, consider contraception as their responsibility, and men play an accessory role, supporting this task.

KEY WORDS: contraception, contraceptive methods, fertility regulation, male participation, support 